\title{
Association between glycated hemoglobin A1c levels with age and gender in Chinese adults with no prior diagnosis of diabetes mellitus
}

\author{
QINGLIN MA ${ }^{1-3}$, HOUMING LIU ${ }^{1}$, GUANGXIN XIANG ${ }^{2}$, WANSHUI SHAN ${ }^{1}$ and WANLI XING ${ }^{2,3}$ \\ ${ }^{1}$ Clinical Laboratory, Shenzhen Third People's Hospital, Shenzhen, Guangdong 518112; \\ ${ }^{2}$ CapitalBio Corp., Beijing 102206; ${ }^{3}$ School of Medicine, Tsinghua University, Beijing 100084, P.R. China
}

Received December 31, 2015; Accepted March 17, 2016

DOI: $10.3892 /$ br.2016.643

\begin{abstract}
The present cross-sectional study consisted of 18,265 Chinese patients not previously diagnosed with diabetes mellitus, and who underwent physical examination at the Third People's Hospital of Shenzhen between June 2014 and May 2015 (mean patient age, 51.312 \pm 15.252 years). The study was composed of 11,770 males and 6,495 females. The aim was to investigate the association between glycated hemoglobin A1c (HbAlc) levels, gender and age. HbA1c values were measured using a Bio-Rad VARIANT ${ }^{\mathrm{TM}}$ II HbA1c Reorder Pack. All data was collected for analysis of the HbA1c levels in different gender and age groups, in order to investigate the association between HbA1c levels and age. Analysis of the 18,265 total cases and 16,734 cases with HbA1c levels $<6.5 \%$, demonstrated a positive correlation between levels of HbAlc and patient age. Linear regression for patient age and HbAlc levels demonstrated that HbA1c $(\%)=0.020 \mathrm{x}$ age $($ years $)+4.523(\mathrm{r}=0.369$, $\mathrm{P}<0.0001)$ and HbA1c $(\%)=0.014 \mathrm{x}$ age $($ years $)+4.659$ $(r=0.485, \mathrm{P}<0.0001)$, respectively. HbA1c levels of the male group were significantly higher than those of the female group $(\mathrm{P}<0.0001)$. Furthermore, in different gender groups, HbA1c levels gradually rose with increasing age. Therefore, HbAlc levels are associated with age and gender in Chinese populations, and this should be considered when selecting HbAlc as a criterion for future diabetes screening.
\end{abstract}

\section{Introduction}

Glycated hemoglobin A1c (HbA1c) is a form of hemoglobin that is measured in order to identify the average concentration

Correspondence to: Dr Wanshui Shan, Clinical Laboratory, Shenzhen Third People's Hospital, 29 Bulan Road, Shenzhen, Guangdong 518112, P.R. China

E-mail: szmiclin@163.com

Dr Wanli Xing, School of Medicine, Tsinghua University, 30 Shuangqing Road, Beijing 100084, P.R. China

E-mail: szjykmiclin@163.com

Key words: glycated hemoglobin Alc, gender, age, Chinese, diabetes mellitus of plasma glucose over the relatively long-term period of two to three months prior to the date of measurement. Since HbAlc testing can be performed at any time of the day and without any special patient preparation (for example, fasting is not required) and provides more accurate information about the disease and the patient, it offers improved convenience for patients and health care providers compared to the oral glucose tolerance test or taking fasting plasma glucose measurements $(1,2)$. On this basis, it has been suggested that HbA1c may serve as a better indicator for glucose control in diabetic patients than fasting blood sugar levels $(3,4)$. Furthermore, HbA1c levels have been proposed as a diagnostic tool for identifying patients with undiagnosed diabetes or that have an elevated risk of developing diabetes (5). In 2011, the World Health Organization and the American Diabetic Association accepted HbA1c levels $\geq 6.5 \%$ as a diagnostic criterion for diabetes mellitus $(6,7)$. However, it is important to take age, race/ethnicity, anemia/hemoglobinopathies (and other diseases for which HbA1c may be an unsatisfactory criterion for the diagnosis of type 2 diabetes) into consideration when using the HbA1c levels to diagnose diabetes (8-15). Further studies are thus required to promote a more appropriate standard for HbAlc in the diagnosis of type 2 diabetes. Furthermore, while HbAlc values have been previously reported to increase with age in Japanese patients (11), there are no reports about the association between HbAlc and gender and age in Chinese adults. In view of whether HbA1c levels may vary with the race or ethnicity of patients $(16,17)$, the present study aims to evaluate the association between gender, age and HbA1c levels in Chinese adults that have not been diagnosed with diabetes mellitus.

\section{Materials and methods}

Study subjects. The present retrospective study comprised of 18,265 Chinese adults (aged 18-99 years, average age $51.312 \pm 15.252$ years; 11,770 males, average age $52.892 \pm 15.445$ years; 6,495 females, average age $48.449 \pm 14.466$ years) who were not known to be suffering with diabetes and who underwent a comprehensive health examination between June 2014 and May 2015 at the Shenzhen Third People's Hospital (Shenzhen, China). The inclusion criteria for 
Table I. Comparison of HbA1c levels of different gender subjects.

\begin{tabular}{|c|c|c|c|c|c|c|}
\hline \multirow[b]{2}{*}{ Groups } & \multicolumn{2}{|c|}{ All personnel } & \multicolumn{2}{|c|}{ HbA1c $<6.5 \%$ personnel } & \multicolumn{2}{|c|}{ HbA1c $\geq 6.5 \%$ personnel } \\
\hline & No. & HbA1c $(\%)$ & No. & HbA1c (\%) & No. & HbA1c $(\%)$ \\
\hline Male & 11,770 & $5.619 \pm 0.894$ & 10,542 & $5.385 \pm 0.446$ & 1,228 & $7.621 \pm 1.212$ \\
\hline Female & 6,495 & $5.454 \pm 0.706$ & 6,192 & $5.347 \pm 0.427$ & 303 & $7.635 \pm 1.400$ \\
\hline t-value & 13.730 & & 5.547 & & -0.178 & \\
\hline P-value & $<0.0001$ & & $<0.0001$ & & 0.859 & \\
\hline
\end{tabular}

All data are presented as the mean \pm standard deviation or as number of participants; comparison of HbA1c levels between male and female was done with independent sample t-test. HbA1c, hemoglobin A1c.

the study was as follows: i) Han ethnicity; ii) age $\geq 18$ years; iii) resident of mainland China for $>1$ year; and iv) no previous diagnosis of diabetes. Exclusion criteria was as follows: Previously known diabetes, pregnancy, heart/liver/kidney dysfunction, long-term oral administration of drugs affecting blood glucose, long-term history of smoking, anemia/hemoglobinopathies, and surgery within the past month $(13,18)$. The age range of the participants was divided into seven groups: 18-29, $30-39,40-49,50-59,60-69,70-79$ and $\geq 80$ years. The study protocol was approved by the Ethics Committee of Shenzhen Third People's Hospital. All the participants included in the present study provided written informed consent.

Sample collection and measurement. A $2 \mathrm{ml}$ venous blood sample was collected in the morning following 8-12 h of overnight fasting. Blood sample HbA1c levels were measured within $2 \mathrm{~h}$ using a high-performance liquid chromatography VARIANT ${ }^{\mathrm{TM}}$ II hemoglobin testing system (Bio-Rad Laboratories, Inc., Hercules, CA, USA). Detection was performed strictly in accordance with the manufacturer's instructions using the original kit, calibration, and quality control. The intra- and inter-assay coefficients of variation for HbAlc were both $<0.8 \%$. All procedures were carried out by trained doctors at Shenzhen Third People's Hospital.

Statistical analysis. All data are presented as the mean \pm standard deviation (SD) for variables with normal distribution, the median (interquartile range) for variables with a non-normal distribution, or as the number of participants. One variable comparison between two groups was analysed using an independent sample t-test. Analysis of one-way ANOVA was first used in multiple groups comparison, and pairwise comparison in multiple groups was conducted using the LSD-T method. Correlation analysis among different variables was performed with Pearson correlation analysis and linear regression. A value of $\mathrm{P}<0.05$ was considered to indicate a statistically significant difference. All statistical analysis was performed using the SPSS software, version 21.0 (IBM SPSS, Armonk, NY, USA).

\section{Results}

Comparison of HbAlc levels in males and females. As shown in Table I, there were significant differences $(\mathrm{P}<0.0001)$ in HbA1c levels between the male and female groups in the total study population (referred to all personnel) and the $\mathrm{HbAlc}<6.5 \%$ (referred to HbA1c $<6.5 \%$ personnel). It specifically demonstrated that the overall levels of HbA1c were higher in male than that in female (Table I).

Comparison of HbAlclevels across different age groups. HbAlc test results for all age groups are shown in Table II and Fig. 1. The data suggested two interesting results: i) HbAlc values of all personnel and HbA1c $<6.5 \%$ personnel, in both males and females, gradually increased with age until 79 years, and then plateaued (Fig. 1); ii) HbAlc levels of $\mathrm{HbA1c} \geq 6.5 \%$ patients of either gender gradually decreased with age (Fig. 1). An independent sample t-test was performed on HbAlc levels for males and females of the same age group. The results showed that the difference of HbA1c values in different gender of 30-59 years old subjects was statistically significant $(\mathrm{P}<0.05)$, and male HbA1c levels were higher than those of females (Table II). The difference in HbAlc levels in different gender of the other four age-groups was not significant $(\mathrm{P}>0.05)$ (Table II).

Correlation between HbAlc levels and age. Linear regression analysis showed that HbA1c levels were positively correlated with age in all personnel (increase of $0.020 \%$ per decade) and $\mathrm{HbA} 1 \mathrm{c}<6.5 \%$ personnel (increase of $0.014 \%$ per decade), the linear regression equations were HbAlc $(\%)=0.020 \times$ age $($ years $)+4.523(\mathrm{r}=0.369 ; \mathrm{P}<0.0001)$ and HbA1c $(\%)=0.014 \times$ age $($ years $)+4.659(\mathrm{r}=0.485$; $\mathrm{P}<0.0001)$, respectively. By contrast, HbA1c levels were negatively correlated with age in $\mathrm{HbA} 1 \mathrm{c} \geq 6.5 \%$ personnel (decreased $0.012 \%$ per decade), the linear regression equation was HbA1c $(\%)=-0.012 \times$ age $($ years $)+8.345(\mathrm{r}=0.124$; $\mathrm{P}<0.0001)$.

\section{Discussion}

The results of the current study suggest that greater attention should be given to patient gender and age when selecting HbA1c as the criterion in diabetes screening, as has been reported in previous studies $(8,11,13,19-21)$. HbA1c levels, which were significantly higher in male than that in female and increased steadily as age rose, differ significantly by gender and age.

The HbAlc levels of male individuals were significantly higher than those of females in the 30-59 years age-groups $(\mathrm{P}<0.05)$. It is most likely due to factors such as blood pressure 
Table II. Comparison of HbA1c levels of different age groups.

\begin{tabular}{|c|c|c|c|c|c|c|c|c|}
\hline \multirow{2}{*}{$\begin{array}{l}\text { Age groups, } \\
\text { years }\end{array}$} & \multicolumn{2}{|c|}{ All personnel } & \multicolumn{2}{|c|}{ Male } & \multicolumn{2}{|c|}{ Female } & \multirow[b]{2}{*}{ t-value } & \multirow[b]{2}{*}{ P-value } \\
\hline & No. & HbA1c (\%) & No. & HbA1c (\%) & No. & HbA1c $(\%)$ & & \\
\hline $18-29$ & 1,380 & $4.994 \pm 0.399$ & 727 & $4.975 \pm 0.405$ & 653 & $5.014 \pm 0.392$ & -1.829 & 0.068 \\
\hline $30-39$ & 2,697 & $5.180 \pm 0.605$ & 1,566 & $5.221 \pm 0.681$ & 1,131 & $5.123 \pm 0.473$ & 4.392 & $<0.001$ \\
\hline $40-49$ & 4,449 & $5.404 \pm 0.700$ & 2,698 & $5.464 \pm 0.790$ & 1,751 & $5.310 \pm 0.519$ & 7.847 & $<0.001$ \\
\hline $50-59$ & 4,905 & $5.695 \pm 0.881$ & 3,308 & $5.718 \pm 0.949$ & 1,597 & $5.646 \pm 0.718$ & 2.954 & 0.003 \\
\hline $60-69$ & 2,329 & $5.852 \pm 0.853$ & 1,548 & $5.875 \pm 0.897$ & 781 & $5.807 \pm 0.759$ & 1.914 & 0.056 \\
\hline $70-79$ & 1,499 & $6.019 \pm 0.950$ & 1,144 & $6.031 \pm 0.958$ & 355 & $5.981 \pm 0.924$ & 0.885 & 0.377 \\
\hline$\geq 80$ & 1,006 & $6.028 \pm 0.858$ & 779 & $6.015 \pm 0.826$ & 227 & $6.072 \pm 0.959$ & -0.872 & 0.383 \\
\hline
\end{tabular}

All data are presented as the mean \pm standard deviation or as number of participants; comparison of HbA1c levels between male and female was done with independent sample t-test. HbA1c, hemoglobin A1c.

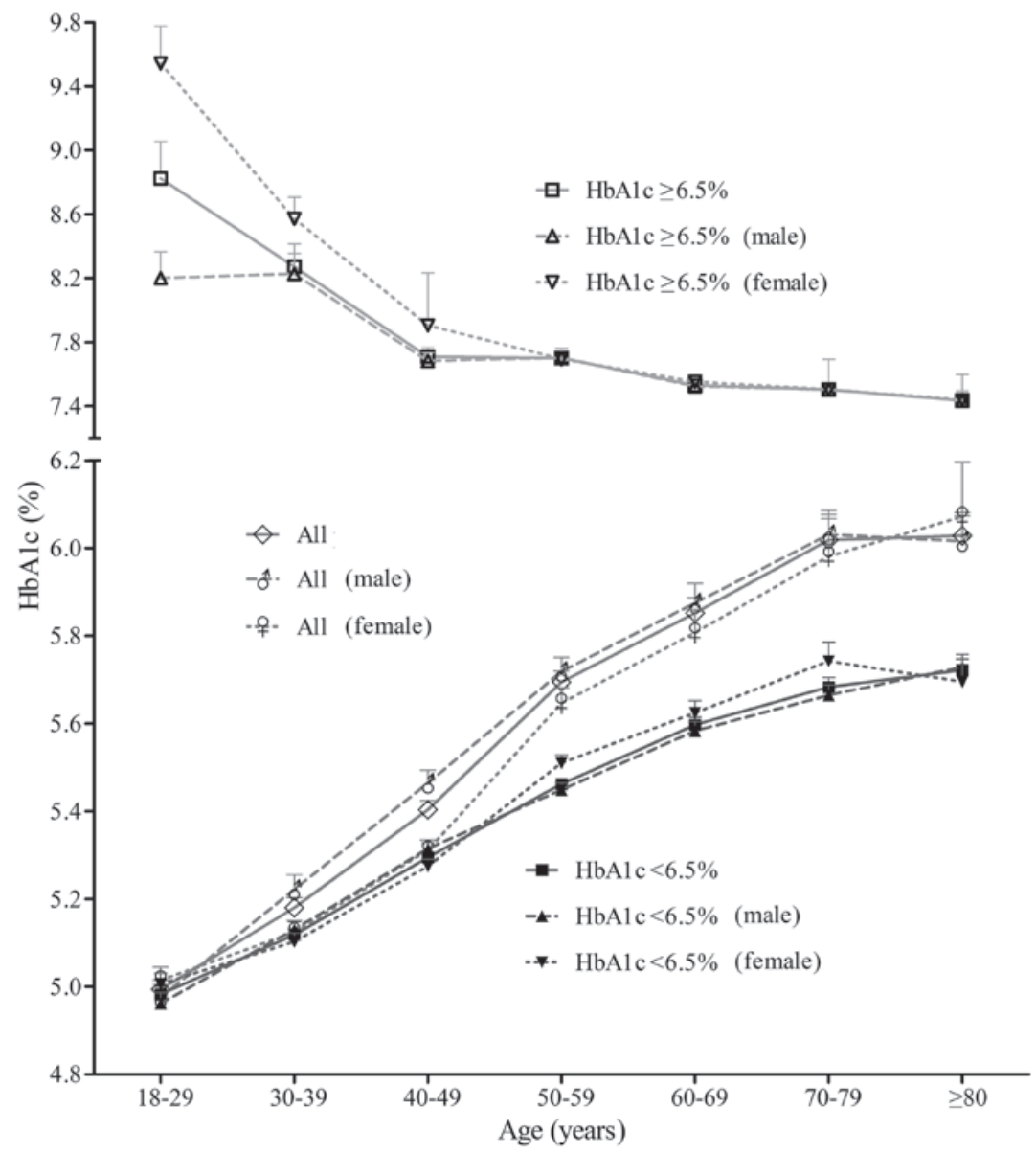

Figure 1. Hemoglobin A1c (HbA1c) levels in seven age categories. Error bars display 95\% confidence intervals in each category.

and blood lipids of males in this age-group have worse control conditions, and women may be easily affected by physiological cycle. As in previous reports (19,22-24), gender differences were noted in the relationship between HbAlc and age. It is possible that this finding is related to lower hemoglobin levels in menstruating women with more rapid erythrocyte turnover, as suggested previously (19). Women in peri- and post-menopausal age-groups had a steeper slope than men.
With increased age, many changes occur in humans, such as: i) The function of pancreatic islets gradually declines; ii) tissue sensitivity to insulin and insulin receptor activity slowly decrease; and iii) muscle tissue gradually reduces and the consumption of glucose generally decreases. Under the combined effect of these factors, blood glucose increases with age incrementally, so that the HbA1c levels are also elevated, especially with advancing age. Moreover, linear regression 
analysis showed that HbAlc levels rose by $0.014 \%$ per decade in $\mathrm{HbA} 1 \mathrm{c}<6.5 \%$ individuals, confirming three previous reports $(21,25,26)$ that indicate age is a significant independent impact factor of HbAlc.

The strengths of our study are the large sample size, the strict but random selection of the population and the wide range of the age distribution. Although our study has an obvious limitation, that of greatly different numbers of men and women participants, we feel that our results are compelling and indicative of the need for further research.

In conclusion, the present study clearly illustrates the effect of gender and age on HbAlc values in Chinese populations, which illustrates the diagnostic titer of HbAlc for diabetes varies in different age/gender groups. Therefore, we suggest that age and gender should be considered in the application of HbAlc for the diagnosis of diabetes.

\section{Acknowledgements}

The present study was supported by grants from the Shenzhen Science and Technology Innovation Committee (grant nos. JCYJ20130401164749996, JCYJ20140411113637598 and JCYJ20140411111718161).

\section{References}

1. Rohlfing CL, Little RR, Wiedmeyer HM, England JD, Madsen R, Harris MI, Flegal KM, Eberhardt MS and Goldstein DE: Use of $\mathrm{GHb}(\mathrm{HbAlc})$ in screening for undiagnosed diabetes in the U.S. population. Diabetes Care 23: 187-191, 2000

2. Kumpatla S, Aravindalochanan V, Rajan R, Viswanathan V and Kapur A: Evaluation of performance of A1c and FPG tests for screening newly diagnosed diabetes defined by an OGTT among tuberculosis patients-a study from India. Diabetes Res Clin Pract 102: 60-64, 2013.

3. Lippi G, Mattiuzzi C and Targher G: Glycated hemoglobin, diabetes, and cardiovascular risk in nondiabetic adults. N Engl J Med 362: 2030-2031, author reply 2031, 2010.

4. Bicescu G: Glycated hemoglobin, diabetes, and cardiovascular risk in nondiabetic adults. Maedica (Buchar) 5: 80-81, 2010.

5. International Expert Committee: International Expert Committee report on the role of the $\mathrm{A} 1 \mathrm{C}$ assay in the diagnosis of diabetes. Diabetes Care 32: 1327-1334, 2009.

6. Metzger BE, Buchanan TA, Coustan DR, de Leiva A, Dunger DB, Hadden DR, Hod M, Kitzmiller JL, Kjos SL, Oats JN, et al Summary and recommendations of the Fifth International Workshop-Conference on Gestational Diabetes Mellitus. Diabetes Care 30 (Suppl 2): S251-S260, 2007.

7. Colagiuri S: Glycated haemoglobin (HbA1c) for the diagnosis of diabetes mellitus - practical implications. Diabetes Res Clin Pract 93: 312-313, 2011.

8. Davidson MB and Schriger DL: Effect of age and race/ethnicity on $\mathrm{HbA1c}$ levels in people without known diabetes mellitus: Implications for the diagnosis of diabetes. Diabetes Res Clin Pract 87: 415-421, 2010.

9. Selvin E, Francis LM, Ballantyne CM, Hoogeveen RC, Coresh J, Brancati FL and Steffes MW: Nontraditional markers of glycemia: Associations with microvascular conditions. Diabetes Care 34: 960-967, 2011.

10. Cohen RM, Franco RS, Khera PK, Smith EP, Lindsell CJ, Ciraolo PJ, Palascak MB and Joiner CH: Red cell life span heterogeneity in hematologically normal people is sufficient to alter HbA1c. Blood 112: 4284-4291, 2008.
11. Inoue $\mathrm{M}$, Inoue $\mathrm{K}$ and Akimoto $\mathrm{K}$ : Effects of age and sex in the diagnosis of type 2 diabetes using glycated haemoglobin in Japan: The Yuport Medical Checkup Centre study. PLoS One 7: e40375, 2012.

12. Kramer CK, Araneta MR and Barrett-Connor E: A1C and diabetes diagnosis: The Rancho Bernardo Study. Diabetes Care 33: 101-103, 2010.

13. Yang L, Shen X, Yan S, Xu F and Wu P: The effectiveness of age on HbA1c as a criterion for the diagnosis of diabetes in Chinese different age subjects. Clin Endocrinol (Oxf) 82: 205-212, 2015.

14. Zhao X, Chang Mei H, Chen L, Jiang L, He M, Chen J, Hu Z, Ye H, Hu H, Zhou L, et al: An increased level of haemoglobin A1C predicts a poorer clinical outcome in patients with acute pancreatitis. Clin Endocrinol (Oxf) 77: 241-245, 2012.

15. Yang L, Shen X, Yan S, Yuan X, Lu J and Wei W: HbAlc in the diagnosis of diabetes and abnormal glucose tolerance in patients with Graves' hyperthyroidism. Diabetes Res Clin Pract 101: 28-34, 2013.

16. Ziemer DC, Kolm P, Weintraub WS, Vaccarino V, Rhee MK, Twombly JG, Narayan KM, Koch DD and Phillips LS: Glucose-independent, black-white differences in hemoglobin A1c levels: A cross-sectional analysis of 2 studies. Ann Intern Med 152: 770-777, 2010.

17. Kumar PR, Bhansali A, Ravikiran M, Bhansali S, Dutta P, Thakur JS, Sachdeva N, Bhadada SK and Walia R: Utility of glycated hemoglobin in diagnosing type 2 diabetes mellitus: A community-based study. J Clin Endocrinol Metab 95: 2832-2835, 2010.

18. Koda M, Kitamura I, Okura T, Otsuka R, Ando F and Shimokata $\mathrm{H}$ : The associations between smoking habits and serum triglyceride or hemoglobin A1c levels differ according to visceral fat accumulation. J Epidemiol, 2015.

19. Yang YC, Lu FH, Wu JS and Chang CJ: Age and sex effects on HbAlc. A study in a healthy Chinese population. Diabetes Care 20: 988-991, 1997.

20. Yates AP and Laing I: Age-related increase in haemoglobin Alc and fasting plasma glucose is accompanied by a decrease in beta cell function without change in insulin sensitivity: Evidence from a cross-sectional study of hospital personnel. Diabet Med 19: 254-258, 2002.

21. Pani LN, Korenda L, Meigs JB, Driver C, Chamany S, Fox CS Sullivan L, D'Agostino RB and Nathan DM: Effect of aging on A1C levels in individuals without diabetes: Evidence from the Framingham Offspring Study and the National Health and Nutrition Examination Survey 2001-2004. Diabetes Care 31: 1991-1996, 2008.

22. Karar T, Alhammad RI, Fattah MA, Alanazi A and Qureshi S: Relation between glycosylated hemoglobin and lipid and thyroid hormone among patients with type 2 diabetes mellitus at King Abdulaziz Medical City, Riyadh. J Nat Sci Biol Med 6 (Suppl 1): S75-S79, 2015.

23. Takao T, Matsuyama Y, Suka M, Yanagisawa H and Iwamoto Y: The combined effect of visit-to-visit variability in HbAlc and systolic blood pressure on the incidence of cardiovascular events in patients with type 2 diabetes. BMJ Open Diabetes Res Care 3: e000129, 2015.

24. Wu CH, Yao WJ, Lu FH, Wu JS and Chang CJ: Relationship between glycosylated hemoglobin, blood pressure, serum lipid profiles and body fat distribution in healthy Chinese. Atherosclerosis 137: 157-165, 1998.

25. Sacks DB, Arnold M, Bakris GL, Bruns DE, Horvath AR, Kirkman MS, Lernmark A, Metzger BE and Nathan DM: Guidelines and recommendations for laboratory analysis in the diagnosis and management of diabetes mellitus. Clin Chem 57: e1-e47, 2011.

26. Sacks DB, Arnold M, Bakris GL, Bruns DE, Horvath AR, Kirkman MS, Lernmark A, Metzger BE and Nathan DM; National Academy of Clinical Biochemistry; Evidence-Based Laboratory Medicine Committee of the American Association for Clinical Chemistry: Guidelines and recommendations for laboratory analysis in the diagnosis and management of diabetes mellitus. Diabetes Care 34: e61-e99, 2011. 